\title{
Mobile Ad Hoc Network Routing Protocols: a Detailed Performance Examination of AODV, DSR and DSDV
}

\author{
Sanjeev Gangwar \\ Department of Computer Application, VBS \\ Purvanchal University Jaunpur
}

\author{
Krishan Kumar \\ Department of Computer Application, Gurukula \\ Kangri Vishwavidyalaya, Haridwar
}

\begin{abstract}
ABSTARCT
The latest technology MANETs is being studied widely and attracting a large variety of applications. Due to varying network topology, The most common challenging factor in MANET is routing [2][3]. In this research paper, we study the performance of reactive routing protocols, Ad hoc on demand Distance Vector (AODV) and Dynamic Source Routing (DSR) and proactive routing protocol Destination Sequenced Distance Vector (DSDV). We study the performance of MANETs routing protocol in high mobility case under low, medium and high density scenario. It becomes important to study the noticeable effect of high mobility on the performance of these routing protocols. We examine in detail the performance of routing protocol with respect to Average End-to-End Delay, Normalized Routing Load (NRL), Packet Delivery Fraction (PDF) and Throughput. Simulation study with NS-2 confirms that AODV provide better performance as compared to DSR and DSDV
\end{abstract}

General Terms

Mobile ad hoc networks, AODV, DSR

Keywords

MANETs, Routing Protocols, NRL, AODV, DSDV, DSR, NS2.

\section{INTRODUCTION}

Mobile ad hoc network (MANET) [1] is defined as an autonomous system of mobile nodes and associated hosts connected by wireless links. Every node operates not only as an end system, but also as a node to forward the packets in appropriate direction. All the nodes are free to move and organize themselves into a network. The important use of mobile ad hoc network is in battlefield. MANETs do not require the support of wired access points or base stations for intercommunication. A mobile ad hoc network, unlike a static network, has no infrastructure. It is a collection of mobile nodes where communication is established in the absence of any fixed foundation. The only possible direct communication is between neighboring nodes. Therefore, communication between remote nodes is based on multiple-hop. (MANETs) are considered as infrastructure-less mobile wireless communication network. An ad hoc network is a group of wireless nodes in which nodes give or receive packets for each other to allow a node to communicate beyond its direct wireless transmission range. Ad hoc networks require no fixed network infrastructure such as base stations or access points and can be building quickly and inexpensive set up as needed. In a MANET, nodes within each other's wireless transmission ranges can communicate directly. However a node which is situated outside the communication range then a node which wants to send a message to another node has to trust on some other nodes to relay its messages [3]. Routing is the most fundamental research issue in MANETs. The Desirable qualitative properties of a routing protocol for MANETs are Distributed operation, Loop-freedom, Demand-based operation, Security, Sleep period operation and unidirectional link support. Some quantitative metrics that can be used to assess the performance of any routing protocol are End-to end delay, throughput, PDF, NRL and Route Acquisition Time etc. Routing protocols for ad hoc networks have some limitations such as high error rates, scalability, security, quality of service, energy efficiency, multicast, aggregation and node cooperation etc. This paper is explained as follows: In section 2, we explain some of the routing protocols used in MANETs. Section 3 explains related work. Section 4 explains Performance metrics for routing protocols. The Simulation study is explained in section 5 . The results are discussed in section 6 . The last section discusses the concluding remarks.

\section{ROUTING PROTOCOLS FOR MANETS}

Routing protocols for wireless ad hoc networks can be mainly arranged into the two categories: Table-driven (or Proactive) and On-demand (or Reactive) [3].

\subsection{Pro-active Routing (Table-driven)}

The information from each node to every node in the network maintains up-to-date information by table driven routing protocols. These protocols require each node to maintain one or more tables to store routing information and they respond to changes in network topology by propagating updates throughout the network in order to maintain a consistent network view. The areas where they differ are the number of necessary routing-related tables and the methods by which changes in network structure are broadcast. The main disadvantage of table driven implementation algorithm is-

i. Requirement for maintenance of a large amount of data at every node.

ii. Slow reaction on restructuring and failures

\subsubsection{Destination Sequenced Distance Vector (DSDV)}

The Destination-Sequenced Distance-Vector Routing protocol (DSDV) presented in [17] is a table-driven algorithm based on the classical Bellman- Ford routing mechanism. The improvements made to the Bellman-Ford algorithm include freedom from loops in routing tables [18]. Every mobile node in the network maintains a routing table in which all of the possible destinations within the network and the number of hops to each destination are recorded. Each entry is marked with a sequence number assigned by the destination node. The sequence numbers enable the mobile nodes to distinguish stale routes from new ones, thereby avoiding the formation of 
routing loops. Routing table updates are periodically transmitted throughout the network in order to maintain table consistency [19]. To help alleviate the potentially large amount of network traffic that such updates can generate, route updates can employ two possible types of packets. The first is known as a "full dump." This type of packet carries all available routing information and can require multiple network protocol data units (NPDUs). During periods of occasional movement, these packets are transmitted infrequently. Smaller "incremental" packets are used to relay only that information which has changed since the last full dump. Each of these broadcasts should fit into a standard size NPDU, thereby decreasing the amount of traffic generated. The mobile nodes maintain an additional table where they store the data sent in the incremental routing information packets. New route broadcasts contain the address of the destination, the number of hops to reach the destination, the sequence number of the information received regarding the destination, as well as a new sequence number unique to the broadcast [17]. The route labeled with the most recent sequence number is always used. In the event that two updates have the same sequence number, the route with the smaller metric is used in order to optimize (shorten) the path. Mobiles also keep track of the settling time of routes, or the weighted average time that routes to a destination will fluctuate, before the route with the best metric is received [17]. By delaying the broadcast of a routing update by the length of the settling time, mobiles can reduce network traffic and optimize routes by eliminating those broadcasts that would occur if a better route was discovered in the very near future.

\subsection{Reactive Routing (On-demand)}

A different approach from table-driven routing is sourceinitiated on-demand routing. This type of routing creates routes only when desired by the source node. When a node requires a route to a destination, it initiates a route discovery process within the network. This process is completed once a route is found or all possible route permutations have been examined. Once a route has been established, it is maintained by some form of route maintenance procedure until either the destination becomes inaccessible along every path from the source or until the route is no longer desired.

\subsubsection{Ad hoc On Demand Distance Vector (AODV)}

AODV is an improvement on DSDV because it minimizes the number of required broadcasts by creating routes on an ondemand basis, as opposed to maintaining a complete list of routes, as in the DSDV algorithm. When a source node wants to send a message to some destination node and does not already have a valid route to that destination, it initiates a path discovery process to discover the other node. It transmit a route request (RREQ) packet to its neighbors, which then forward the request to their neighbors, and so on, until either the destination or an intermediate node with a "fresh enough" route to the destination is located. AODV utilizes destination sequence numbers to make certain that all routes are loop-free and contain the most recent route information. Each node maintains its own sequence number, as well as a broadcast ID. The broadcast ID is incremented for every RREQ the node initiates, and together with the nodes IP address, uniquely identifies a RREQ. Along with its own sequence number and the broadcast ID, the source node includes in the RREQ the most recent sequence number it has for the destination. Intermediate nodes can reply to the RREQ only if they have a route to the destination whose corresponding destination sequence number is greater than or equal to that contained in the RREQ.

\subsubsection{Dynamic Source Routing (DSR)}

The Dynamic Source Routing (DSR) protocol presented in [20] [16] is an on demand routing protocol that is based on the concept of source routing. Mobile nodes are required to maintain route caches that contain the source routes of which the mobile is aware. Entries in the route cache are continually updated as new routes are learned. DSR also has the capability to handle unidirectional links. Since DSR discovers routes on-demand, it may have poor performance in terms of control overhead in networks with high mobility and heavy traffic loads. Scalability is said to be another disadvantage of DSR.in DSR, when a mobile (source) needs a route to another mobile (destination), it initiates a route discovery process which is based on flooding. The source originates a RREQ packet that is flooded over the network. The RREQ packet contains a list of hops which is collected by the route request packet as it is propagated through the network. Once the RREQ reaches either the destination or a node that knows a route to the destination, it responds with a RREP along the reverse of the route collected by the RREQ [7]. This means that the source may receive several RREP messages corresponding, in general, to different routes to the destination. DSR selects one of these routes, and it maintains the other routes in a cache. The routes in the cache can be used as substitutes to speed up the route discovery if the selected route gets disconnected. To avoid that RREQ packets travel forever in the network, nodes, that have already processed a RREQ, discard any further RREQ bearing the same identifier.

\section{RELATED WORK}

To determine the performance of the routing protocols Chenna R. et al. [9], Talooki and Ziarati [10] and Lakshmikant et al. [11] gives a detailed simulation of DSDV, AODV, DSR and TORA with 50 wireless nodes forming ad hoc networks and the paper concluded that DSDV and TORA show good performance in a network with low mobility whereas AODV and DSR maintain comparatively better performance in all mobility situations. Mahdipur E, et. Al [12] evaluated the performance of DSDV and AODV routing protocols in MANETs under CBR traffic with NS-2 [8]. Performance comparison of AODV and DSR routing protocols in a constrained situation is done in [13]. The authors claim that the AODV outperforms DSR in normal situation but in the constrained situation DSR out performs AODV, where the degradation is as severe as 30\% in AODV whereas DSR degrades marginally as $10 \%$. Though both AODV and DSR use on demand route discovery, they have different routing mechanics. Perkins et all [14] observe that, for application oriented metrics such as delay and throughput, DSR outperforms AODV when the numbers of nodes are smaller. AODV outperforms DSR when the number of nodes is very large. The authors show that DSR consistently generates less routing load than AODV.

\section{PERFORMANCE METRICS}

Following four performance metrics are to be considered to compare the three routing protocol.

1. Average End-to-End Delay: It is defined as the average time taken by the data packets to propagate from source to destination across a MANET. This includes all possible delays caused by buffering during routing discovery latency, 
queuing at the interface queue, and retransmission delays at the MAC, propagation and transfer times.

2. Normalized Routing Load (NRL): The number of routing packets transmitted per data packet delivered at the destination.

3. Packet Delivery Fraction (PDF): This is the ratio of the number of data packets successfully delivered to the destinations to those generated by sources. Packet Delivery Fraction $=$ received packets/sent packets $* 100$

4. Throughput: It is the rate of successfully transmitted data packets in a unit time in the network during the simulation

\section{SIMULATION SETUP}

We use the Network Simulator NS-2 [9] for performing the network simulation. The traffic sources are Constant Bit Rate (CBR). The source destination pairs are spread randomly over the network. The mobility model uses 'random waypoint model' in a rectangular field of $1000 \mathrm{~m} \times 1000 \mathrm{~m}$ with 25 nodes to 200 nodes. Different network scenario for different number of nodes for 5 connections and 10 connections are generated. In Table -1 , we have summarized the model parameters that have been used for our experiments.

\section{Table-1}

\begin{tabular}{|l|l|}
\hline Parameter & Parameter Value \\
\hline Simulator & NS-2.33 \\
Simulation Area & $1000 \mathrm{~m}$ X 1000m \\
MAC Protocol & IEEE 802.11 \\
Mobile Nodes & $25,50,75,100,125,150$, \\
Antenna Type & 175,200 \\
Propagation Model & Omni antenna \\
Number of Connections & Two Ray Ground \\
Packet Size & 5,10 \\
Routing Protocols & 512 byte \\
Traffic Sources & AODV, DSDV \& \\
Simulation Time & DSR \\
Mobility Model & CBR (UDP) \\
Pause Time & 100 Sec. \\
& Random waypoint \\
\hline
\end{tabular}

\section{RESULTS}

In this section we compare three MANETs routing protocol. Simulations results are collected from a total of 60 scenarios of the three protocols. By varying number of sources, comparison between the three protocols can be done using line graph.

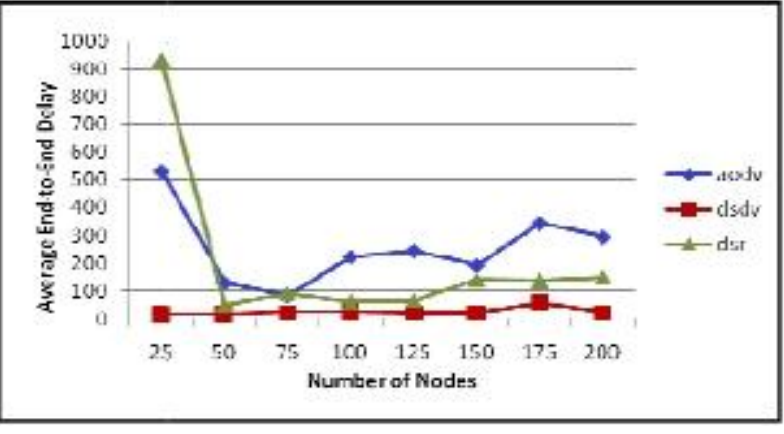

Figure 1. Average End-to-End Delay vs. Number of Nodes (with 5 Connections)

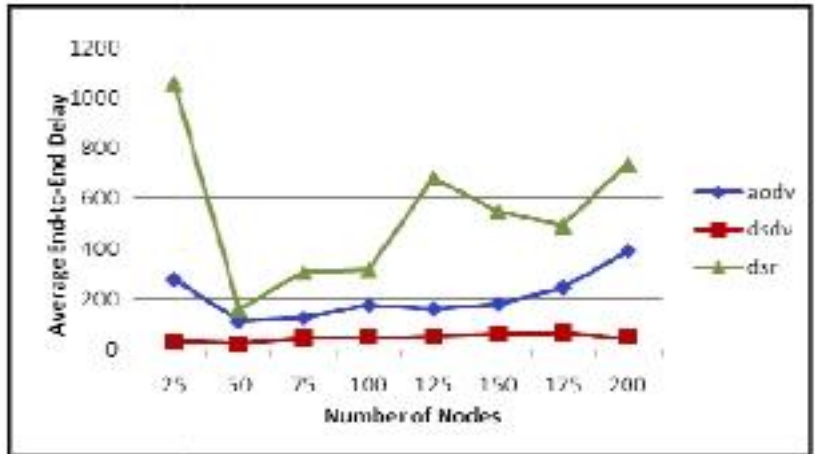

Figure 2. Average End-to--End Delay vs. Number of Nodes (with 10 Connections)

In Figure 2, we noticed that the performance of DSR is degrading due to increase in the number of nodes in the networks. The performance of the AODV is slightly better. Average delay is less for DSDV routing protocol and remains constant as the number of nodes increases.

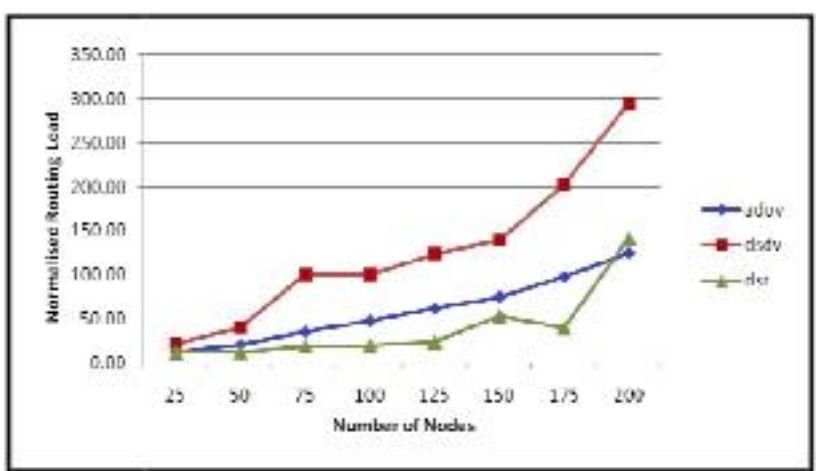

Figure 3. Normalized Routing Load vs. Number of Nodes (with 5 Connections)

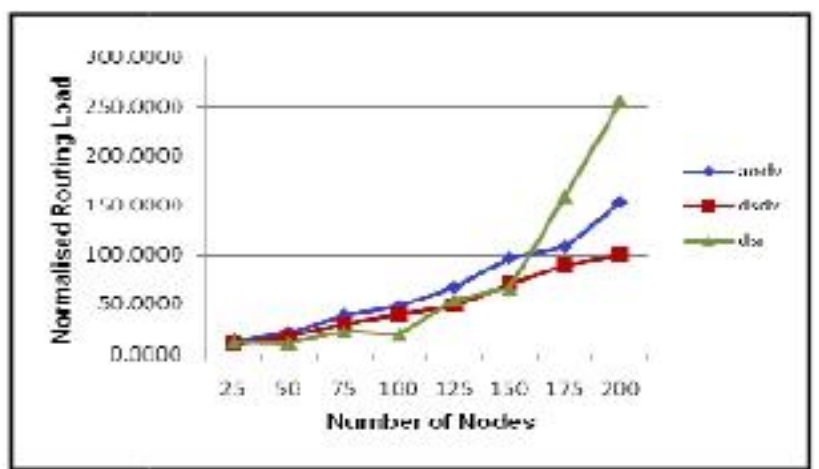

Figure 4. Normalized Routing Load vs. Number of Nodes (with 10 Connections)

Normalized routing load (NRL) of AODV, DSDV and DSR protocols in different sources are presented in Figure 3 and Figure 4. In Figure 3 (5 connection/source), AODV and DSR demonstrate lower routing load. Proactive routing protocol DSDV showed higher routing load than the reactive routing protocols AODV and DSR. In Figure $4 \quad(10$ connection/source), as Network load is increased, Normalized Routing Load of AODV and DSR is much higher than the DSDV. In this simulation, due to high congestion in the adhoc network, AODV requires more routing packets to maintain transmission of data packets. We have used the same simulation environment path, mobility and traffic patterns for 
these three protocols and AODV has consistent and worse NRL as the number of nodes is increased.

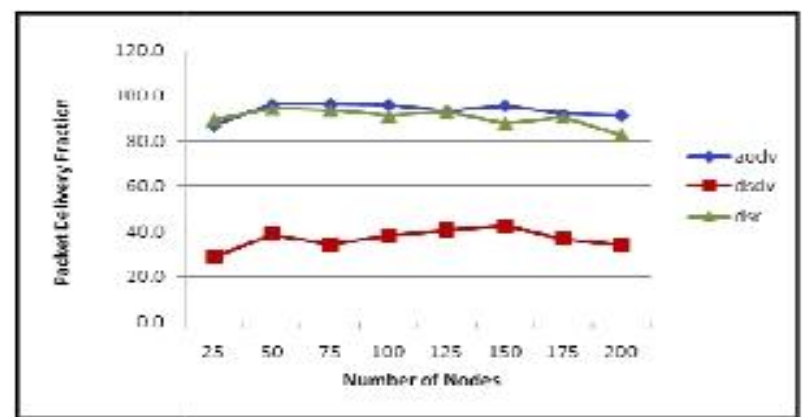

Figure 5. Packet Delivery Fraction vs. Number of Nodes (with 5 Connections)

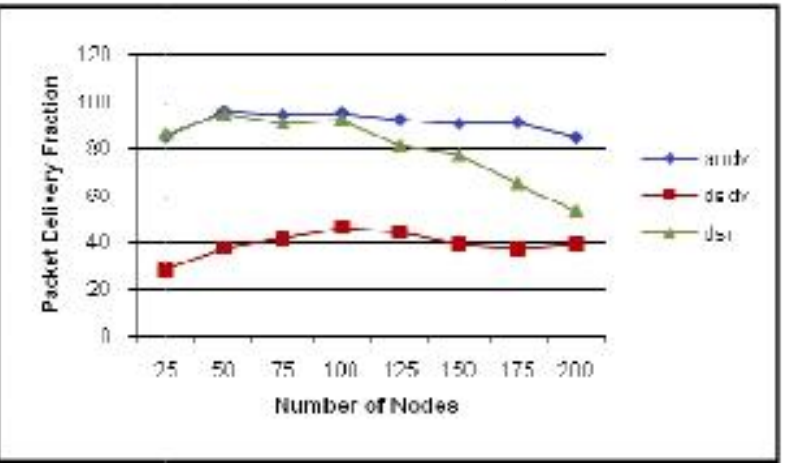

Figure 6. Packet Delivery Fraction vs. Number of Nodes (with 10 Connections)

In Figure 5, we have noticed a slight advantage to AODV when the number of nodes is increased in mobile networks. Overall, the data packet delivery ratio of AODV and DSR is higher in a scenario with high mobility than that of DSDV.

Figure 6 shows that the AODV manages to deliver a greater fraction of data packets in scenarios with high mobility in large mobile networks. We observe that DSR routing protocol performs well when the number of nodes is less, however its performance declines drastically with increased number of nodes in the network. The performance of DSDV is better when the number of nodes is increasing in the network.

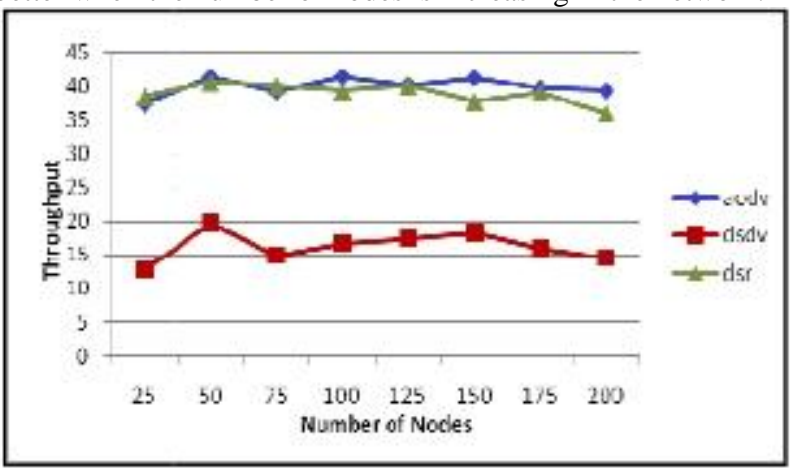

Figure 7. Throughput vs. Number of Nodes (with 5 Connections)

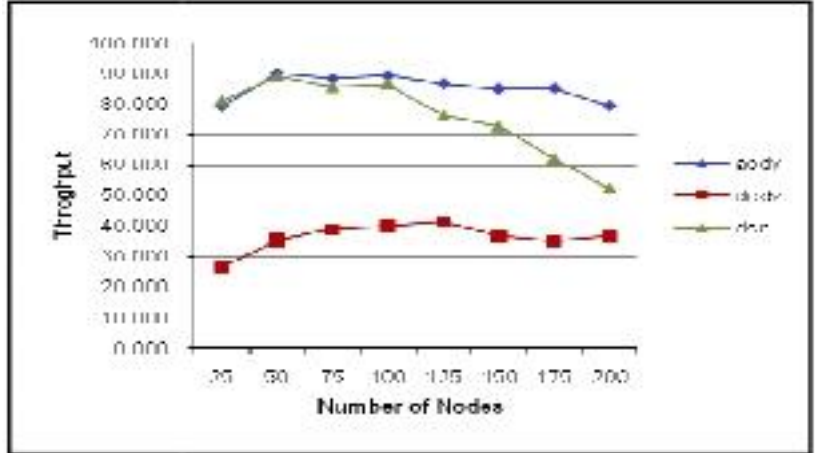

Figure 8. Throughput vs. Number of Nodes (with 10 Connections)

From the above Figure 7 and Figure 8 it is clear that AODV gives better throughput and outperforms even the DSR

Table-2 Result Analysis

\begin{tabular}{|c|c|c|c|}
\hline $\begin{array}{l}\text { Average End-to-End } \\
\text { Delay }\end{array}$ & NRL & PDF & $\begin{array}{l}\text { Through } \\
\text { put }\end{array}$ \\
\hline $\begin{array}{l}\text { Performance } \\
\text { Degrade with } \\
\text { number of nodes } \\
\text { increase in the } \\
\text { networks }\end{array}$ & $\begin{array}{ll}\text { Consistent } & \text { and } \\
\text { worse } & \\
\text { NRL } & \text { when } \\
\text { increasing } & \\
\text { number of nodes. }\end{array}$ & Best & Best \\
\hline $\begin{array}{l}\text { Least and remains } \\
\text { constant as the } \\
\text { number of nodes } \\
\text { increase in the } \\
\text { networks }\end{array}$ & $\begin{array}{l}\text { Higher routing } \\
\text { load } \\
\text { than the AODV } \\
\text { and } \\
\text { DSR. }\end{array}$ & Least & Least \\
\hline $\begin{array}{l}\text { Degrade when } \\
\text { number of nodes } \\
\text { increase in the } \\
\text { Networks. }\end{array}$ & $\begin{array}{l}\text { Much higher than } \\
\text { the } \\
\text { AODV when } \\
\text { network } \\
\text { load is increased. }\end{array}$ & \begin{tabular}{|l} 
Performs \\
well \\
when the \\
number of \\
nodes is \\
less \\
but \\
declines \\
drastically \\
when the \\
numbers \\
of \\
nodes are \\
increased.
\end{tabular} & $\begin{array}{l}\text { Better } \\
\text { than } \\
\text { DSDV }\end{array}$ \\
\hline
\end{tabular}

\section{CONCLUSION}

Simulation study shows the performance of three routing protocols AODV, DSR and DSDV. This paper study the performance of routing protocols, used in MANETs, in high mobility case under low, medium and high density scenario. We vary the number of nodes from 25 (low density) to 200 (high density) in a fixed topography of $1000 \times 1000$ meters. Moreover, since Random Waypoint Mobility Model has been used in this study to generate node mobility, we take an average of 10 randomly generated scenarios so to make a detailed performance analysis. We find that the performance varies widely across different network sizes and results from one scenario cannot be applied to those from the other scenario. AODV performance is the best considering its 
ability to maintain connection by periodic exchange of information. As far as Throughput is concerned, AODV and DSR perform better than the DSDV even when the network has a large number of nodes. Simulation work shows that AODV performs better in a network with a larger number of nodes whereas DSR performs better when the number of nodes is small. Average End-to-End Delay is the least for DSDV and does not change if the no of nodes are increased. Thus, we find that AODV is a viable choice for MANETs but NRL for AODV increases at a higher rate compared to that in DSDV \& DSR with increase in number of nodes in networks. In this paper, we have done complete analysis of the three MANET's routing protocols.

\section{REFERENCES}

[1] Sanjeev Gangwar, Dr. Krishan Kumar (2011) "Mobile Ad hoc Networks: A detailed survey of QoS Routing Protocols" Vol.2 N0.-6 in International Journal of Distributed and Parallel Systems.

[2] Akshai Aggarwal, Savita Gandhi and Nirbhay Chaubey "A Study of Secure Routing Protocol in Mobile Ad hoc Networks" in Proceedings of National Conferences on Advancement in Wireless Technology and Applications, 18-19 December 2008, SVNIT, Surat, India.

[3] Akshai Aggarwal, Savita Gandhi and Nirbhay Chaubey "Key Management Consideration in MANETs" in Proceedings of National Conference on Cryptography and Network Security (NCCNS),18-19 February 2009, VIT Unviersity, Vellore, India.

[4] Charles E. Perkins, Ad Hoc Networking, AddisonWesley, March 2005.

[5] Charles E. Perkins and Pravin Bhagwat, "Highly Dynamic destination-sequenced distance vector routing (DSDV) for mobile computers. 1994.

[6] C. Perkins, E Royer and S. Das "Ad hoc On-demand Distance Vector (AODV) Routing," RFC 3561 , July 2003.

[7] David B. Johnson, David A. Maltz "Dynamic Source Routing in Ad Hoc Wireless Networks, Mobile Computing, Thomasz Imielinski and Hank Korth (Editors) ," Vol. 353, Chapter 5, pp. 153-181, Kluwer Academic Publishers, 1996

[8] NS-2 Network simulator http://www.isi.edu/nsnam/ns
[9] Chenna R. Chandrasekhar P., Reddy P "Performance Analysis of Adhoc Network Routing Protocols, ISAUHC 2006 pp. 186-187

[10] Talooki, Ziarati VNK "Performance Comparison of Routing Protocols for Mobile Ad-hoc Networks, APCC 2005 pp $1-5$

[11] Lakshmikanth, Gaiwak G, Vyavahare MA," Simulation based comparative performance analysis of Adhoc routing protocols TENCON- 2008 pp 1-5

[12] Mahdipou E, Aminian E, Torabi M, Zare M “ CBR Performance Evaluation over AODV and DSDV in RW Mobility Model, ICCAE 2009 pp 238-242.

[13] R. Misra, C. R. Manda (2005) "Performance Comparison of AODV/DSR On-Demand Routing Protocols for Ad Hoc Networks in Constrained Situation", IEEE ICPWC 2005.

[14] S. R. Das, C. E. Perkins and E. M. Royer (2000), "Performance comparison of Two On-Demand Routing protocols for Ad hoc Networks", In Proc. of INFOCOM 2000, Tel Aviv, Israel, March 2000.

[15] Marc Greis' Tutorial for the UCB/LBNL/VINT Network Simulator "ns". http://www.isi.edu/nsnam/ns/tutorial/

[16] Network Simulator - 2 (NS-2) http://mohit.ueuo.com/NS-2.html

[17] S. Murthy and J. J. Garcia-Luna-Aceves, "An Efficient Routing Protocol for Wireless Networks," ACM Mobile Networks and Applications Journal, Special Issue on Routing in Mobile Communication Networks, pp. 183197,October 1996.

[18] Tao Lin, "Mobile Ad-Hoc Networks Routing Protocols Methodologies and Applications", PhD Thesis, Virginia Polytechnic Institute and State University, 2004.

[19] David Remondo, "tutorial on wireless Ad Hoc networks". Department of telematics engineering EPSC, Second international working conference in performance modeling and evaluation of heterogeneous networks. Ilkley,West Yorkshire, U.K., July 2004.

[20] Swati Sinha Deb. A new distributed QoS routing algorithm based on Fano's method. Computer Networks, Volume 48, Issue 2, 6 June 2005, Pages 155-174. 